\title{
MERCOSUL E SOCIEDADE CIVIL
}

Luiz Eduardo W. WanderLey

\begin{abstract}
Resumo: Os pontos principais referem-se a aspectos parciais de uma pesquisa em andamento sobre "gestão pública estratégica dos governos subnacionais diante dos processos de inserção internacional e integração latino-americana", desenvolvida por equipes dos quadros da Fundap, do Cedec e da PUC-SP. Das três partes constituintes do projeto temático, serão feitas referências àquela pertinente à participação da sociedade civil no processo de integração regional, tendo por centro o Mercosul.
\end{abstract}

Palavras-chave: governos subnacionais; sociedade civil; Mercosul.

Abstract: The main points of this article are extracted from a research project that is currently underway entitled "Strategic Public Strategies of Sub-National Governments Within the Context of the Processes of Latin American Global Insertion and Integration" carried out by researchers from Fundap (Foundation for Public Administration), Cedec, and the Catholic University of São Paulo. Reference will be made to a section of the study dealing with the participation of civil society in regional development, in this case, in the context of Mercosul. Key words: sub-national governments; civil society; Mercosul.

A ntes de apresentar as reflexões referentes à temática central deste artigo, serão feitos breves comentários sobre certas questões vinculadas à compreensão do significado da integração regional e suas incidências mais diretas ao assunto em pauta. Na seqüência, salientam-se alguns tópicos para o entendimento do significado de sociedade civil.

Sobre a temática da integração regional, uma longa citação de Goudard e Jordan (1997:93-94) indica bem os ângulos que se pretende destacar neste texto. "As uniões regionais da primeira geração surgiram prioritariamente para resolver problemas interiores às suas zonas, nas quais os países tinham geralmente necessidade de mais abertura. $\mathrm{Na}$ Europa, em 1951 e em 1957, os signatários dos Tratados de Paris e de Roma queriam consolidar a paz sobre o continente, modernizar o setor de carvão e do aço, dotar-se de um mercado interior ampliado que permitisse produções mais competitivas e mais rentáveis, e estimular tecnologias novas. Aqueles da Aele (...), em 1960, tinham em vista uma fórmula provisória (ela durará mais de 30 anos!), para se prepararem a uma cooperação econômica regional mais estreita, mas dividindo os domínios da política comercial e da agricultura. No mesmo ano, o Tratado de integração da
América Central e o da zona de livre comércio da América Latina (Alalc, depois Aladi) repousaram sobre preocupações da mesma ordem para os espaços concernidos. Hoje, com a segunda vaga regionalista, o desafio é experimentado como uma ameaça proveniente do exterior, contra a qual a união regional espera então se proteger, se colocar numa melhor posição de negociação. (...) É precisamente o que explica que os Estados Unidos - que sempre foram hostis em participar de uma zona de integração somente na América - se converteram à solução regional, com o Canadá em 1988, e depois em prol da Alena em 1992. Para eles, concretamente, os concorrentes europeus e do sudeste asiático retiravam suas partes de mercado dos Estados Unidos: era preciso discriminá-los e, com a Alena, dispôs de um melhor contrapeso em face das uniões regionais no restante da Tríade. Desde então, contrariamente ao período 19501960 , as uniões regionais são agora menos constituídas para elas mesmas do que por reação às interferências com outras zonas" (Quadros 1 e 2).

Mesmo considerando-se a necessidade de uma atualização das informações apresentadas nos Quadros 1 e 2, ficam evidenciados os dois momentos formativos dos blocos regionais e a mudança de enfoque em cada um deles. 
O Mercosul, independente de outros motivos - na interpretação de Ginesta (1999), a opção por este Bloco em particular se deve a uma perspectiva do Brasil de liderança continental madura e integração na economia internacional, de uma maneira vantajosa para os seus interesses - atravessa uma fase de tentativa de apoio nos países-membros e mesmo mais além (Chile), para entrar na Alca com maiores trunfos de negociação. Algumas tratativas de estender acordos com a União Européia em geral - o que tem sido bastante difícil principalmente para vencer o protecionismo agrícola que naquela região é tradicional e bem assegurado - vão no sentido de obter parceiros importantes e melhorar os termos das futuras negociações com os Estados Unidos, cujo poder hegemônico torna delicada eventuais pressões para ganhos significativos dos países latino-americanos.

Sobre a explicitação de certos ângulos do conceito de sociedade civil, foram esboçados, em texto anterior (Wanderley, 1999), determinados componentes, com base em idéias expostas por Gramsci, que são retomados aqui com a finalidade de assinalar aspectos relevantes na presente análise:

- incorporar, somando-se aos elementos constitutivos da concepção gramsciana de sociedade civil (ideologia, filosofia, artes, ciência, religião e aparelhos privados de hegemonia), tudo aquilo que constitui a esfera pública (caracterizada pela presença dos seguintes componentes constitutivos: visibilidade social, controle social, democratização, confrontação pública, cultura pública) e que não se confunde com a esfera estatal;

- reafirmar, na concepção de Gramsci, a visão da mútua relação entre sociedade política e sociedade civil, que nas conjunturas históricas pode oscilar ora com a prevalência da hegemonia, ora com a prevalência da dominação;

- enfatizar, ao lado da idéia de consenso, o aspecto conflitivo que permeia todas as dimensões da vida social, que não se reduz aos conflitos de classes, mas é causado também por diferenças de raça, de sexo, de religião, de cultura, etc.;

- ampliar a idéia de direção intelectual e moral, com as noções de direção social e direção política - esta última conduzida não por um partido único, mas por vários partidos e por outros condutos políticos (conselhos, por exemplo) e pela presença de associações e movimentos que contribuem para dar consistência à identidade dos setores e classes sociais envolvidos e para sua ação mais concertada;
- reforçar a noção de que não há separação nem descolamento da infra-estrutura (mercado) com a superestrutura (sociedade civil e sociedade política), considerando que estão organizadamente interligadas na constituição do bloco histórico; ligação que é empreendida não somente pelos "intelectuais orgânicos" das classes fundamentais do capitalismo, mas por representantes de outras classes e setores sociais não-classistas (por exemplo, dos grupos religiosos, das minorias étnicas), dos setores envolvidos com formas de propriedade alternativa (propriedade comunitária, autogestionária, pública não-estatal) e de produção alternativa (como, por exemplo, economia solidária);

- destacar, no caso latino-americano e, particularmente, no brasileiro, o surgimento dos movimentos sociais (populares e de outra natureza - de gênero, ecológicos, indígenas, de negros, de direitos humanos, etc.), geradores de novos sujeitos sociais que fortaleceram a sociedade civil nas últimas décadas, trazendo práticas inovadoras que questionaram práticas tradicionais implementadas pelo Estado e pelo mercado, tais como o rompimento com o "reinado de privilégios".

Nos marcos teóricos esboçados pelo grupo de pesquisa em foco, a tese central defendida (Wanderley e Raichelis, 2001), a respeito de uma efetiva participação dos governos subnacionais (e mesmo nacionais) associados às forças vivas da Sociedade Civil, convergia para um esforço de conceituação mais rigoroso do que se entende por gestão pública nos marcos de uma sólida democracia. Isto derivava da compreensão de como todos os interessados ocupavam o espaço público. Partia-se do pressuposto de que, mesmo reconhecendo como um patamar necessário a conquista e o fortalecimento da democracia liberal representativa, em sua dimensão político-institucional, o que no nosso continente já significa um avanço exponencial, uma democracia sólida e fecunda deve incluir sem tergiversações as dimensões econômica e social. Se alguns passos foram conseguidos com a emergência e o funcionamento dos Estados de Bem-Estar Social em determinadas regiões do mundo, problemas derivados da explosão da atual globalização (perda da soberania do Estado-Nação, predomínio do capital financeiro, fluxos comerciais abundantes, mas que privilegiam os países ricos, presença decisiva das multinacionais, passagem da etapa do fordismo para a da acumulação flexível) e do domínio do neoliberalismo (desregulamentação, redução do Estado, precarização do trabalho, privatização, ajuste estrutural, Consenso de Washington) e as imensas e per- 


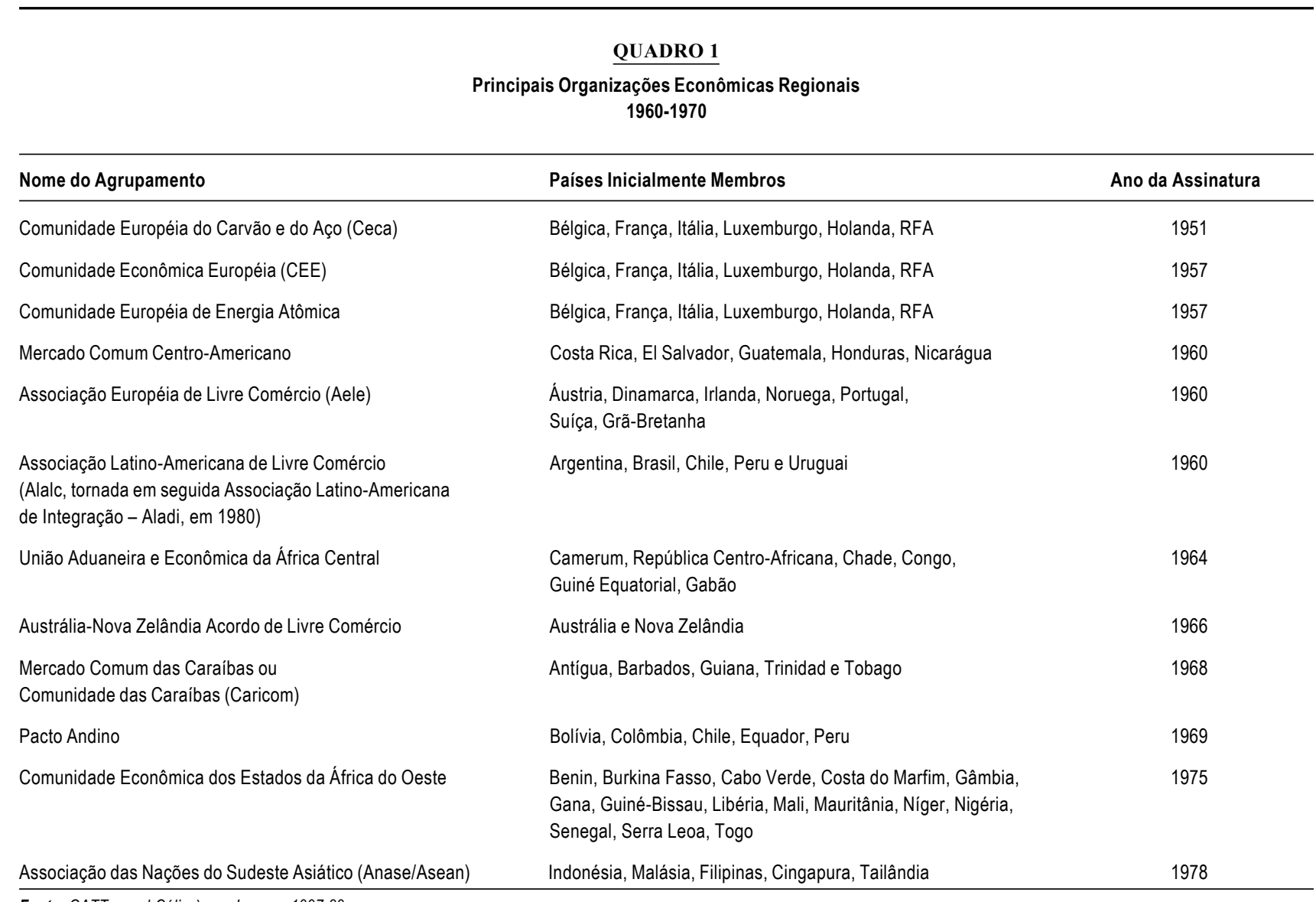

Fonte: GATT, apud Célimène e Lacour, 1997:89.

\section{QUADRO 2}

Principais Organizações Econômicas Regionais 1980-1990

\begin{tabular}{|c|c|c|}
\hline Nome do Agrupamento & Países Inicialmente Membros & Ano da Assinatura \\
\hline Pacto Andino (1) & Bolívia, Colômbia, Equador, Peru, Venezuela & maio 1987 \\
\hline Canadá - USA Acordo de Livre Comércio & Canadá e Estados Unidos & janeiro 1988 \\
\hline União do Magreb Árabe & Algéria, Líbia, Marrocos, Mauritânia, Tunísia & fevereiro 1989 \\
\hline Associação das Nações do Sudeste Asiático (Anase/Asean) (1) & $\begin{array}{l}\text { Brunei Darussalam, Indonésia, Malásia, } \\
\text { Filipinas, Cingapura, Tailândia }\end{array}$ & janeiro 1991 \\
\hline Mercado Comum do Sul (Mercosul) & Argentina, Brasil, Paraguai, Uruguai & março 1991 \\
\hline Espaço Econômico Europeu & CEE e Aele (salvo a Suíça) & maio 1992 \\
\hline Associação de Livre Comércio Norte-Americana (Alena/Nafta) & Canadá, México, Estados Unidos & dezembro 1992 \\
\hline Acordo de Livre Comércio da Europa Central (Cefta) & Hungria, Polônia, República Tcheca, República Eslováquia & dezembro 1992 \\
\hline União Européia (Tratado de Maastricht) (2) & CE & fevereiro 1993 \\
\hline Acordo de Livre Comércio Grupo dos Três & Colômbia, Venezuela, México & junho 1994 \\
\hline
\end{tabular}

Fonte: GATT, apud Célimène e Lacour, 1997:90.

(1) Reativação do Agrupamento.

(2) Aprofundamento da União. 
versas conseqüências no social (aumento da pobreza e da exclusão social, desemprego estrutural, perda de direitos) engendraram, nos últimos anos, um panorama que vem pondo em risco a própria sobrevivência da democracia.

Acentuava-se que o interesse público deve tornar a gestão pública mais permeável às demandas emergentes da sociedade, e reduzir a tendência do Estado, do poder burocrático e dos agentes sociais privilegiados de monopolizar as esferas de decisão política. Nas condições históricas e estruturais brasileiras, nas quais houve sempre uma privatização do Estado por parte das elites (econômicas e políticas principalmente, mas não só), gerando mesmo uma cultura de apropriação do público pelo privado, faz-se necessário um processo contínuo de publicização que impregne a sociedade, que permita mobilizar espaços de representação, interlocução e negociação entre os atores sociais, que dinamize novas formas de articulação/integração entre Estado e Sociedade Civil em que interesses coletivos possam ser explicitados e confrontados. Com as particularidades típicas de cada Estado-Nação, essa privatização do público permeia todas as sociedades do continente.

Visualizando o público como construção social - uma conseqüência a ser atingida na luta democrática -, é indispensável colocar a sociedade, principalmente os setores organizados, com instrumentos de representação e protagonismo (Cunill Grau, 1998). O paradigma tecnocrático hegemônico busca a eficiência da ação governamental em um processo de concentração, centralização e fechamento do processo decisório, e alargamento das prerrogativas presidenciais. A "eficácia da gestão seria reduzida à noção de insulamento burocrático, implicando basicamente a capacidade de o Estado isolar-se das pressões políticas e sociais" (Diniz, 1999).

Com esse enquadramento, foram destacadas algumas categorias analíticas como base para a investigação, quais sejam: visibilidade social, controle social, representação de interesses coletivos, democratização e cultura pública (Wanderley, 1996 e 1999).

Trazendo a temática para o plano das relações internacionais, no modelo cosmopolita de democracia, Held o define como "um modelo de organização política na qual os cidadãos, qualquer que seja sua localização no mundo, têm voz, entrada e representação política nos assuntos internacionais, paralela e independentemente de seus respectivos governos" (Archibugi e Held apud Gómez, 1998).

Em contraposição aos processos ambivalentes de globalização, surgem os sinais efetivos de uma "sociedade civil global", ainda emergente, pela difusão e consolidação da democracia no interior das nações, regiões e redes globais. "O Estado-Nação não pode mais reivindicar para si a condição de único centro de poder legítimo nas suas próprias fronteiras, ao mesmo tempo que deve assumir um papel mediador de diferentes lealdades nos planos subnacional, nacional e internacional; a cidadania, por sua vez, passa a conhecer formas mais elevadas de participação e representação em estruturas supranacionais e, simultaneamente, formas mais 'reduzidas em escala', com incremento de poder em comunidades locais e grupos subnacionais" (Linklater apud Gómez, 1998).

Nessa direção, contudo, as lutas por criação de mecanismos mundiais, como, taxação de operações financeiras globais (o imposto Tobin), o julgamento de crimes contra a humanidade por Cortes de Justiça internacionais (caso do ex-presidente da Iugoslávia, Slodoban Milosevic), o affaire Pinochet, o surgimento do Fórum Social Mundial, as ações do Green Peace, entre outros, são exemplos de casos nos quais a democracia cosmopolita e a cidadania mundial direcionam-se para uma "sociedade civil global".

Ainda muito longe do estabelecimento de meios supranacionais de elaboração de diretrizes macroeconômicas, de resolução de controvérsias, de efetivação de direitos, pode-se aspirar à formação de uma "sociedade civil americana", ou "sociedade civil do Mercosul"? Sim, como possibilidade ainda muito remota e se elas forem visualizadas com toda a prudência devida, requerendo, para isso, que os imensos obstáculos da presente realidade sejam vencidos e que a vontade política de governantes e grupos organizados seja revigorada para conseguir criar os meios indispensáveis para sua consecução. Não, se prevalecerem as rivalidades e antagonismos intra e interpaíses, e se permanecerem hegemônicos os modelos de sociedade e de organização econômica atualmente vigentes.

No quadro latino-americano e com acentuada implicação na presente conjuntura brasileira, vale o alerta de Gómez (1998:33) "Os governos radicalmente comprometidos com as reformas pró-mercado, em lugar de buscar o apoio mais amplo possível através de negociações e pactos e de um forte envolvimento das instituições representativas, empenham-se em enfraquecer e tornar ineficazes as oposições partidárias e sindicais e o próprio jogo das instituições democráticas em benefício do mais puro decisionismo autoritário e estilo tecnocrático de governo. Desse modo, o processo democrático fica reduzido ao ritual eleitoral, decretos-lei e explosões fragmentadas de protesto; a participação declina e o debate político desa- 
parece; o Estado diminui e a política-espetáculo se entroniza pela mão dos meios de comunicação como mais uma prática de consumo simbólico; os partidos políticos, sindicatos e organizações sociais representativas enfrentam a alternativa do consentimento passivo ou das explosões extraparlamentares; a corrupção e a falta de responsabilidade no manejo dos assuntos públicos vão juntas com a degradação da cultura cívica e dos laços de solidariedade no próprio seio da sociedade civil, contribuindo assim a reforçar uma cidadania extremamente passiva".

Nos limites da pesquisa em curso, e tendo como pano de fundo as demarcações feitas, foram estabelecidas algumas hipóteses que, se se considerar os fatos dos últimos anos e a crise acirrada dos últimos meses, sobretudo a da Argentina, e mesmo que não se tenham ainda as conclusões finais dessa pesquisa, parece que podem ser validadas. A primeira é a de que quanto maior for a esfera pública democrática em cada Estado-membro, maior será a possibilidade de uma integração regional abrangente. Tomando por base as enormes dificuldades vivenciadas pelos governos da Argentina e do Brasil (e que podem ser estendidas para os demais países) para consolidar mecanismos e práticas democráticas efetivas, seus reflexos fazem-se sentir na atual conjuntura de existência de grandes incertezas quanto à própria sobrevivência do Mercosul e seu futuro, o que pode ser exemplificado com a desvalorização do real (medida não anunciada aos parceiros naquela ocasião e que ocasionou tensões marcantes), e com as medidas propostas (com a presença do ministro Cavallo) e em operação no caso argentino que afetam de forma direta o nosso país, gerando atritos de monta. A falta de consulta e de se levar em conta a opinião pública das sociedades civis desses países - que, é evidente, ainda guardam ressaibos de um passado de desconfianças e tensões, e que não estão sendo conscientizadas para o valor da integração regional, mesmo ressalvando determinadas exceções minoritárias e de relativo alcance político (como se ponderará a seguir) - demonstram como o processo integrador vem sendo quase inteiramente forjado de "cima para baixo", com gestões públicas pouco democráticas, minimizando o potencial que poderia ser brandido.

A segunda hipótese é a de que quanto maior for o processo de publicização existente nas instituições e diretrizes do Mercosul, maior a possibilidade de avançar em conquistas públicas nos Estados-membros. Ainda que não haja instâncias supranacionais capazes de influenciar as decisões nacionais em relação a determinados assuntos, como é a situação da União Européia, as poucas decisões consensuais tomadas pelos agentes protagonistas podem balizar avanços públicos em cada país envolvido, como foi o caso acontecido com o Paraguai no momento em que os governos dos demais países coordenaram uma tomada de posição, propondo eventuais represálias, na eventualidade de se instalar uma instabilidade política não democrática naquele país. A instituição do Foro Consultivo Econômico e Social (FCES), com todos os enormes limites em seu funcionamento, sobretudo com a atuação das centrais sindicais obteve espaços de diálogo positivos.

Outra hipótese central baseia-se na proposição de que sem a resolução da questão social o processo de integração regional padece de substantividade e a democracia não se sustenta. Partindo da concepção dominante que desvincula o plano econômico, do político e do social, que cogita em crescimento econômico na lógica do mercado e ignora o desenvolvimento humano e sustentável, que contrapõe os atores tecnoburocratas e os político-sociais, que leva os governantes e setores empresariais, em geral, a descurarem do social, encarando-o como algo subordinado ou efeito automático do econômico, que usa o social como tema retórico, não há uma preocupação verdadeira no encaminhamento das questões sociais. Daí os embates permanentes com os trabalhadores organizados e crises sucessivas nos países do Bloco, nos quais as condições sociais existentes são de extrema perversidade e vulnerabilidade.

Interessante constatar que, no período dessa pesquisa, outra pesquisa estava sendo desenvolvida por Castro Vieira (2001:20), e desvinculada dessa, propondo como tese e hipótese central a mesma orientação: "a hipótese central do trabalho é que o Mercosul não se consolida como Comunidade Regional devido aos limites impostos à participação da sociedade civil no processo decisório de integração, em face do exclusivismo negociador associado às burocracias governamentais". "Esta tese demonstra que o processo de integração do Mercosul, ao contemplar basicamente aspectos econômicos e comerciais, ao relegar a um segundo plano as políticas sociais, traz à tona o perigo de ser mais um processo de exclusão social (Castro Vieira, 2001:287)."

O que se pode reafirmar, com constatações preparadas por analistas e estudiosos do assunto, em diversas partes do mundo, é a proposição fundamental de que sem a presença consciente e ativa da sociedade civil nos processos integrativos eles perdem consistência em curtos prazos e são atingidos por conflitos intra e intergovernos. Tomando por exemplo a União Européia, foi com base na mobi- 
lização de contingentes expressivos das populações concernidas, por múltiplos meios, que as autoridades mudaram estratégias e planos de ação. Contudo, mesmo nela, não obstante os esforços ingentes para aperfeiçoar a legitimação democrática, o grande número de cidadãos e a variedade geográfica e cultural impedem que haja um relacionamento mais direto. Para ter uma idéia do que é denominado por "cidadania da União", vale registrar alguns direitos e liberdades decorrentes dela, de que gozam os cidadãos nacionais dos Estados-membros (Piepenschneider apud Weidenfeld e Wessels, 1997):

- o direito de residir em qualquer país da União Européia;

- o direito de cada cidadão de votar e ser eleito para o Parlamento Europeu em seu país de residência;

- nos países terceiros, cada cidadão da União pode solicitar a assistência e a proteção diplomática e consular de qualquer outro Estado-membro, se o seu próprio país não dispuser de qualquer tipo de representação;

- o direito de apresentar petições ao Parlamento Europeu, e o direito de recorrer ao Provedor de Justiça; a União Européia tem de respeitar os direitos do homem e as liberdades fundamentais, tal como definidas na Convenção Européia dos Direitos do Homem, e as decorrentes das tradições constitucionais comuns aos Estados-membros.

Mantendo ainda a referência da União Européia, mesmo na condição de órgão consultivo, é de se lembrar a atuação do Comitê Econômico e Social, constituído de 222 representantes de grupos de trabalhadores, patronato e interesses diversos - profissões liberais, agricultura, cooperativas, câmaras de comércio e associações de consumidores. Apesar de sua eficácia reduzida para salvaguardar os interesses dos distintos grupos econômicos e sociais, por sua natureza consultiva, o que leva esses grupos a optarem pela via da influência direta junto com a Comissão Européia, o Comitê tem procurado, com a ajuda de outras organizações européias, ampliar suas ações para melhorar as relações entre os cidadãos da União e as respectivas instituições, e procurado influir de forma direta no processo legislativo (Schley apud Weidenfeld e Wessels, 1997).

Está-se muito longe dessas conquistas e se fazem necessários esforços redobrados de todos os interessados para que se chegue a atingir patamares crescentes nesse sentido. No entanto, algo semelhante aconteceu com os passos efetuados nos debates e documentos elaborados para a adoção da Carta de Direitos Fundamentais do Mercosul (apresentada aos governos em 1994), que posteriormente foi abortada. Em 1998, foi aprovada a Declaração
Sociolaboral do Mercosul, na reunião do Conselho do Mercado Comum, mas que não tem caráter vinculativo aos direitos e às obrigações derivados dos acordos entre os países. Sua validade é a de funcionar "como um instrumento que garanta o cumprimento de um conjunto restrito de direitos fundamentais individuais e que, ao mesmo tempo, estabelece mecanismos que viabilizem a negociação coletiva e um espaço de solução de conflitos entre os segmentos econômicos e sociais e/ou países. Portanto, a Declaração permite uma maior visibilidade dos efeitos da integração comercial e da ação das empresas" (Castro Vieira, 2001:215). A Declaração propõe a definição de um espaço social nas discussões do Bloco, um conjunto de garantias e o reconhecimento das Convenções da OIT como fonte jurídica. Propugnam-se como princípios irrenunciáveis a democracia política e o respeito irrestrito aos direitos civis e políticos. Centralmente, a Carta contém uma percepção do processo de integração como uma possibilidade histórica para melhorar as condições de vida das sociedades nacionais, um apelo aos governos para propor uma eficaz intervenção dos Estados que garantam os direitos dos trabalhadores. A posição perante a livre circulação da mão-de-obra é a de garantir no Bloco igualdade de direitos, condições de trabalho, condições dignas de vida, moradia, educação e saúde. Na perspectiva dos direitos coletivos, propõe a liberdade sindical, a negociação coletiva, o direito à greve, o direito a permanente informação e consulta dos outros órgãos do Mercosul. As Recomendações da OIT para serem ratificadas eram 35 , das quais os quatro países em conjunto só assinaram 11.

Em Declaração apresentada à Cúpula Presidencial (dezembro, 1997), os representantes do Foro manifestavamse: "Deve-se tomar consciência de que o FCES está especificamente qualificado como interlocutor capaz de opinar, contribuir positivamente para a tomada de decisões pelos órgãos técnicos e políticos do MERCOSUL e expressar as preocupações e expectativas de nossas sociedades. Esse foi o espírito e a finalidade que motivou a criação do FCES no Protocolo de Ouro Preto. Mas, na prática, Senhores Presidentes, ainda não se concretizou, pois apesar de haver tratado nestes 18 meses de temas de vital importância, nenhuma consulta lhe foi formalizada". Situação que se repete em 1998: "O FCES poderá cumprir com seu papel de agente consultivo se for devidamente consultado, dentro de um processo onde disponha das devidas informações e condições para a elaboração de suas Recomendações, situação que até o momento não ocorreu" (Ata da VI Reunião Plenária do FCES). 
A posição predominante nas centrais sindicais é bastante crítica, levando em conta que o Subgrupo de Trabalho que deveria ter colocado em seu centro as questões sociais e trabalhistas reduziu-as a problemas de ordem técnica; os encontros entre empresários, governos e trabalhadores concentraram-se em debates voltados para harmonizações de legislações trabalhistas dos quatro países. Os temas debatidos entre empresários e governos analisavam basicamente os interesses comerciais e a promoção e defesa do princípio da competitividade empresarial. Para elas, o que se busca no setor empresarial é uma maior concorrência para reduzir custos trabalhistas. E o que se pretende no setor governamental é implementar as reformas internas - reformulação do Estado, flexibilização trabalhista, desregulamentação econômica -, de acordo com as receitas neoliberais.

"A reação dos governos diante das propostas de garantia de direitos trabalhistas básicos supranacionais sempre é defensiva, pois alegam que vincular direitos sociais ao acordo pode criar precedentes protecionistas, afetar a soberania nacional e a intergovernabilidade do Mercosul" (Castro Vieira, 2001:216).

Com este pano de fundo, lança-se luz sobre uns poucos ângulos da pesquisa, que privilegiou, na parte correspondente à participação da sociedade civil, dois segmentos: empresariado e trabalhadores.

No que tange ao empresariado, há que se considerar inicialmente que a inserção das empresas brasileiras no Mercosul realizou-se muito mais por suas potencialidades individuais do que por uma estratégia organizada. As empresas de grande porte têm capacidade e autonomia para formular suas políticas e estão sempre atentas para quaisquer mercados que ofereçam melhores condições de lucratividade, em quaisquer lugares mais vantajosos em que se situem, nos vários continentes. Se o Mercosul consolidar-se e o Bloco oferecer condições objetivas para a expansão de seus negócios - como atestam os sinais do passado recente no qual houve uma atuação mais agressiva de um conjunto delas na região e um crescimento das exportações brasileiras, com especial destaque para o Estado de São Paulo -, é evidente que seu interesse poderá ser ampliado.

Já para os empresários, pequenos e médios, há grande falta de informações sobre as possibilidades abertas pelo Bloco. A situação é conhecida, e para convencê-los das oportunidades na região, vários tipos de incentivos foram criados, como, cursos, palestras, assessoria, eventos, programas especiais de acesso a crédito, etc. Nessa direção, criou-se inclusive a Associação de Empresas Brasileiras para a Integração no Mercosul, cujo objetivo principal centra-se em informar e capacitar empresários para a importância da integração econômica. Os Estados de Santa Catarina e do Rio Grande do Sul têm favorecido a opção por maior inserção regional.

Uma hipótese sobre as dificuldades de uma maior mobilização do empresariado está na ausência de uma organização que seja capaz de unificar o setor em seu conjunto e pressionar os governos e a sociedade para atenderem às suas demandas. "A predominância da lógica setorial e de interesses particulares enfraquece o movimento mais amplo. As concessões pontuais, que na maioria das vezes trazem grandes benefícios a um determinado grupo de empresas, tomam o lugar de políticas gerais que possam beneficiar o setor privado de maneira geral" (Degenszajn, 2001). Algumas federações de empresários têm-se mobilizado mais, como é o caso dos Estados do Sul, e, em São Paulo, a Fiesp tem tentado certa coordenação, inserindo uma instância específica em sua estrutura para o Mercosul. Nos Estados de Santa Catarina e do Rio Grande do Sul, "a criação e o funcionamento de instâncias, quer de natureza governamental - como a existência de organismos dentro de secretaria estaduais -, quer de natureza empresarial - com a existência de organismos internos das entidades de classe - deixaram entrever com claridade a sua importância e seu significado como um fator de estímulo e colaboração indispensável para que a atuação do empresariado se realize" (Tomazoni, 2001).

Foi destacado, nas entrevistas, que a participação conjunta dos representantes de empresários e trabalhadores, no Foro Econômico e Social, tem sido produtiva e, não obstante as discordâncias óbvias, criou oportunidade de um aprendizado democrático.

Um dado interessante a ser salientado é a existência do chamado Grupo Brasil, criado em 1994, como um ator social significativo. Reúne atualmente cerca de 200 empresas, responsáveis pela geração de 11 mil empregos, na Argentina. Aglutina também empresas argentinas com interesses no Brasil. A entidade promove eventos de caráter político, econômico, social e cultural, os chamados "ambientes de integração", bem como missões comerciais em cidades do interior daquele país. Procura dirimir controvérsias e assessorar os empresários. Dedica-se, ainda, a colocar em contato autoridades dos dois países, tendo realizado reuniões com os presidentes (Fernando Henrique, Menem, De la Rúa) para tratar de questões ligadas ao Mercosul. Um fato relevante foi a articulação do Grupo com o BNDES, para concessão de linha de crédito finan- 
ciando empresas brasileiras com investimentos na Argentina, e argentinos que já possuem investimentos no Brasil.

Pelo lado dos trabalhadores, desde os primórdios da proposta integradora, definiu-se um "apoio crítico" ao Mercosul, com intuito de firmar a integração regional como uma necessidade, mas questionar o tipo de integração pretendido, em razão de orientações da política econômica de corte neoliberal.

As grandes mudanças que vêm afetando os trabalhadores, com a acumulação flexível, a reestruturação produtiva, e suas seqüelas de precarização, desemprego estrutural, rupturas sindicais, entre outras, que acontecem nos planos mundial e nacional, condicionam as análises, que se possam fazer, por regiões. Dada a realidade heterogênea deles na região, com situações diferenciadas nos diversos países, as oportunidades e riscos podem incidir, como vem acontecendo, a fim de maiores ou menores custos, permanentes ou transitórios, pior ou melhor distribuídos.

Como é sabido, o reconhecimento formal da presença desse segmento na estrutura do Bloco foi consagrado com a criação do Foro Consultivo Econômico e Social (FCES). $\mathrm{Na}$ esfera organizativa, as Centrais Sindicais dos paísesmembros, fortaleceram sua articulação por meio da Coordenadora de Centrais Sindicais do Cone Sul (CCSCS). Com base em sua atuação dela, tem havido uma presença constante nas reuniões importantes do Mercosul, procurando apresentar na agenda as demandas dos trabalhadores e da sociedade civil em geral, com as dificuldades anteriormente apontadas.

Na primeira etapa da pesquisa, a participação dos trabalhadores brasileiros no Mercosul enfatizou a presença da Central Única dos Trabalhadores. Desde os primórdios (1991), esta Central demonstrou uma postura bastante crítica com os rumos assumidos, sobretudo pelo desconhecimento nas orientações e ações da questão social, e seu compromisso era o de uma integração regional que aprofundasse os processos democráticos na região, favorecendo a justiça social e o crescimento econômico. Em sua perspectiva, o critério dominante na gestação do Bloco foi o da competitividade, que suplantou o de desenvolvimento, e a realidade maior é a da hegemonia do capital financeiro internacional, que enfatiza o aprofundamento dos processos de liberalização comercial. A integração, na óptica governamental, respondia aos interesses dos credores externos e às políticas de ajuste estrutural, mesmo com recessão interna, e o foco era o crescimento do comércio exterior.
Com os avanços pretendidos de constituição da Alca, tanto a CCSCS como a CUT posicionaram-se contrárias a ela por entenderem que a integração ficaria dependente dos interesses do Bloco do norte do continente, sob a supremacia dos Estados Unidos. O que implicaria mais perdas para os trabalhadores.

A posição da Central, em geral, é de privilegiar a unidade da CCSCS como instrumento útil de dinamização dos setores trabalhistas do Mercosul, em que pese reconhecer os seus limites. Com a crise setorial, nos ramos têxtil e calçadista, em 1999, por ocasião da I Cúpula Sindical do Mercosul, na qual a CUT teve grande participação, as Centrais acordaram relançar o Bloco social e culturalmente. "Os desafios para a CUT são permanentemente redefinidos e novos problemas aparecem. Um deles é como dinamizar a CCSCS. Em 1999 as duas mobilizações conjuntas das centrais sindicais - o Primeiro de Maio celebrado no Uruguai e a I Cúpula Sindical - apontam o surgimento de um cenário viável para sua recomposição como força impulsora da dimensão social no Mercosul" (Trotta, 2001).

A presença mais efetiva nas estruturas do Bloco faz-se com a participação no espaço do Foro Econômico e Social, lugar em que, não obstante as diferenças explícitas de interesses dos membros constituintes, conseguem-se articular algumas negociações ainda que precárias.

Entretanto, as dificuldades são gigantescas. Na afirmação de Chaloult (apud Castro Vieira, 2001:220): "O desafio dos trabalhadores consiste em pensar a atuar como uma classe trabalhadora regional e progressivamente continental, em construir uma estratégia comum e em estabelecer novos parâmetros de relações com os empresários, os quais são, cada vez mais, integrados e subordinados a decisões supranacionais".

Na opinião de outra pesquisadora - que também teve como referência central o Mercosul -, houve várias razões para que o movimento sindical não atingisse seus objetivos: “(...) amplitude de suas propostas, desvinculação de suas demandas da agenda negociadora dos governos, concentração dos trabalhos em temas técnicos e a fragilidade política do movimento sindical naquele momento. Porém, o principal motivo do movimento sindical não ter conseguido atingir seus objetivos mais ambiciosos no Mercosul foi por não dispor de qualquer instrumento de barganha em relação aos governos do bloco regional e em virtude da pressão sindical estar diretamente relacionada à sua capacidade mobilizadora. (...) Outro fator que prejudicou a atuação sindical no Mercosul foi a disparidade entre os interesses 
das centrais, que tiveram dificuldade para formular objetivos comuns, porque às vezes o benefício de uma delas significava fortes perdas para as demais. Um fato interessante é que as discussões técnicas acirraram estas disputas ao evidenciarem as diferenças entre os países e ao expor as desvantagens de cada uma em relação a determinados temas" (Pasquariello Mariano, 2001:269).

Fora do âmbito desses segmentos sociais, surgem outras forças organizadas que têm por escopo alimentar a pretendida integração regional e participar ativamente do processo. Na esfera universitária, universidades individualmente e grupos de universidades formaram-se, atuando em espaços delimitados (como por exemplo, Arcam, Mercosul nas Universidades) e agindo por diversos meios para criar uma consciência e interferir de algum modo no processo, que vão de dissertações e teses, eventos acadêmicos, publicações, até parcerias institucionais entre instituições dos países-membros para intercâmbio de docentes e de estudantes e para a realização de atividades conjuntas. Já tradicionais, é de se registrar a presença de professores e pesquisadores com expressiva contribuição à reflexão latino-americana, que se reúnem sob os auspícios da Faculdade Latino-Americana de Ciências Sociais (Flacso) e do Conselho Latino-Americano de Ciências Sociais (Clacso) com irradiação em distintos países do continente e em particular no Cone Sul.

Associações profissionais inserem-se nesse conjunto, defendendo a presença ativa da sociedade civil e a colocação na agenda do Mercosul da questão social, além de instrumentos de regulamentação profissional: “A criação, defesa e consolidação da regulamentação legal da profissão, de códigos de ética e de formação profissional com bases comuns na região, a partir de princípios decididos em forma coletiva, autônoma e democrática, que garantam o livre exercício da profissão, com direitos e obrigações assegurados de acordo aos marcos jurídicos e em situação de reciprocidade legal" (Princípios éticos y políticos para las organizaciones profesionales de Trabajo Social del Mercosur, 1999).

Tem havido, ademais, um esforço crescente de aglutinar e dar consistência a fóruns e redes que envolvem organizações não governamentais, movimentos sociais, terceiro setor, etc., dotados de maior ou menor alcance e eficácia.

No campo cultural, o intercâmbio de artistas, cineastas, romancistas, músicos, teatrólogos e de outras categorias, pessoal especializado na mídia, grupos étnicos indicam facetas emergentes de uma eventual sociedade civil regional, do Bloco e mesmo mais ampla.
Por fim, uma alusão ao intercâmbio de militantes de partidos políticos, de espectro que recobre todas as tendências político-ideológicas, e que elaboram estratégias, documentos, ações integradas, no sustento de seus objetivos programáticos.

Toda essa constelação de atores, processos, atividades sinaliza a busca embrionária de instituição de uma sociedade civil, débil, limitada, pouco organizada, que descortina um horizonte de esperança, já que ancorada em fatos concretos tangíveis.

\section{NOTA DE CONJUNTURA}

Este artigo já estava escrito e entregue aos editores quando, como conseqüência dos acontecimentos perpetrados pelos ataques terroristas a alvos nos Estados Unidos, se prevê uma profunda inflexão nas relações internacionais. Os cenários anunciados e prescritos, presentes e futuros, são ainda dotados de ampla imprevisibilidade (guerra mundial ou guerras de "baixa intensidade", destruição de nações, perda de direitos civis em nome da segurança, xenofobia, discriminações de toda a espécie, etc.). Alguns indicadores seguem exatamente esses prognósticos e há manifestações concretas que os atestam (mobilizações insufladas de populações propondo guerras santas, combates do bem contra o mal, ações psicossociais que visam identificar posturas políticas com determinadas religiões, criação de inimigos latentes e potenciais no Ocidente e no Oriente, acirramento de racismos étnicos, e assim por diante). Contudo, sua concretização e consolidação vão depender de uma constelação de variáveis de extrema complexidade, e a prudência exige contenção na feitura de prognósticos seguros.

Para os objetivos aqui delineados, breves comentários incidem de forma direta sobre a temática aqui exposta. Por um lado, constata-se enorme consenso entre analistas de diferentes concepções, visto que a data encerra um ciclo e inicia um outro ciclo, no qual estaria esboçando-se uma "nova ordem mundial". Creio que é temerário aceitála como vem sendo anunciada e referendar alguns dos caminhos como fatos consumados, e é preciso aguardar um tempo antes de se posicionar com o desejável descortínio. Basta atentar para as provas inferidas das afirmações categóricas de alguns arautos em um passado recente, logo após a queda do socialismo real, pregando o "fim da história" e o estabelecimento do "pensamento único", que os próprios fatos encarregaram-se de contrariar. Por outro lado, indo na contramão dessa perspecti- 
va, incensada pela maioria da mídia internacional, pessoas, grupos, instituições e setores populacionais mobilizam-se para opor-se à esta (des) ordem mundial em curso, denunciar certo "terrorismo ideológico" que se pretende impor às nações, congregar-se efetivamente pela paz, e avançar na linha de que "um outro mundo é possível".

Em função dos temas específicos analisados neste artigo, pode-se aventar umas poucas hipóteses, como perspectivas futuras, assim resumidas:

- Contrariamente às teses neoliberais de desregulação do Estado e de direção hegemônica do Mercado, que se ancoram de modo exemplar nos Estados Unidos, as medidas até agora propostas pelo governo Bush com o intuito de criar mecanismos de maior segurança e de impulsionar a economia do país, oferecendo para isso importâncias astronômicas de investimento estatal a partir do Executivo, com o apoio quase unânime do Congresso, fazem ressurgir com vigor idéias keinesianas que levam a reconsiderar novamente o papel do Estado.

- A necessidade de apoio logístico, para combate ao terrorismo no plano mundial, tem levado os Estados Unidos em sua estratégia atual contra o Afeganistão (e a eventualidade já proclamada nos discursos das autoridades de ir além e atacar outros países hospedeiros de terroristas), por uma parte, a ignorar a ONU e tomar iniciativas independentes, alegando seu "direito de defesa" e, por outra parte, a propor alianças e conseguir apoios para essa causa em todos os continentes, ampliando com certo ineditismo, e mesmo riscos futuros, seu raio de ação para EstadosNação com quem suas relações internacionais são de conflito, de afastamento, de subordinação e de competição. $\mathrm{O}$ que pode afetar o equilíbrio de forças nacionais e regionais.

- Com relação à América Latina, sempre ressaltando que é muito cedo para chegar a posições conclusivas, tanto pode haver uma aceleração do movimento em direção à constituição da Alca e a uma maior presença norte-americana na região (até mesmo pela vertente da segurança regional e do combate ao narcotráfico), quanto pode haver maiores restrições à alocação de recursos em países em crise (Argentina e Brasil, por exemplo) em função da desaceleração da economia mundial, como também certo "abandono" da mesma Alca.

- Divergências que afloram na condução das políticas macroeconômicas por parte dos governos argentino e brasileiro, bem como qual deva ser a modalidade de inserção desses países na presente conjuntura internacional, dificul- tam sobremaneira a consolidação do Bloco. As presentes dificuldades existentes na Argentina e a aposta no Mercosul (pelo menos no discurso governamental) trouxeram mudanças de peso nas relações entre os dois países, configurando certo retrocesso na história do Bloco, ao se adotarem salvaguardas nas regras que o regem (uma medida para defender a produção Argentina da excessiva desvalorização do real, e que vinha sendo solicitada desde 1999). Procura-se manter a TEC, porque a União Européia só negocia uma zona de livre-comércio com o Mercosul se ela for mantida, e não ferir as regras da OMC. As primeiras reações, de empresários brasileiros que participaram do Fórum de Líderes do Mercosul, em São Paulo (Folha de S.Paulo, B4, 10/10/2001), foram de descontentamento, pela falta de clareza das posições governamentais, pela possibilidade de se manter o protecionismo para certos setores e por não estarem claros os setores que serão atingidos pelas salvaguardas, o que, em sua opinião, afetará o livre comércio e prejudicará a indústria brasileira.

\section{REFERÊNCIAS BIBLIOGRÁFICAS}

ABONG. "Mercosul: integração regional e cidadania". In: ALOP/ABONG/ MLAL. Revista da Abong. São Paulo, n.25, jun. 1998.

ALMEIDA, P.R. Mercosul: fundamentos e perspectivas. São Paulo, LTD, 1998.

BERNAL-MEZA, R. Sistema mundial y Mercosur - globalización, regionalismo y politicas exteriores comparadas. Argentina, Nuevohacer/ Universidad Nacional del Centro de la Provincia de Buenos Aires, 2000.

BIRLE, P.; BRUERA, S. et alii. Dos estúdios sobre los empresários y la integración regional. Montevidéu, Eppal, 1994.

CAMPBELL, J. (ed.). Mercosul: entre a realidade e a utopia. Rio de Janeiro, Relume Dumará, 2000.

CAMPOS, Í.W. e ARROYO, M. “A força do empresariado no Brasil e na Argentina”. Lua Nova. São Paulo, Cedec, n.4, 1998.

CASTILLO, G. et alii. Los trabajadores y el Mercosur. Buenos Aires, Corregidor, 1996.

CASTRO VIEIRA, J, de. Dinâmica polieconômica do Mercosul frente à globalização. Tese de Doutorado. Brasília, UNB/Centro de Pesquisa e Pós-Graduação sobre a América Latina e o Caribe, 2001.

CÉLIMÈNE, F. e LACOUR, C. L'intégration régionale des espaces. Paris, Economica, 1997.

CUNILL GRAU, N. Repensando o público através da sociedadenovas formas de gestão pública e representação social. Rio de Janeiro, FGV, 1998.

CUNILL GRAU, N. e BRESSER PEREIRA, L.C. (orgs.). O público não-estatal na reforma do Estado. Rio de Janeiro, Fundação Getúlio Vargas, 1999.

DEGENSZAJN, A.R. “O empresariado paulista como ator político no Mercosul". Bolsa de iniciação científica, $2^{\circ}$ Relatório Científico. São Paulo, Fundap/Cedec/PUC-SP, abr. 2001. 
DINIZ, E. "Globalização, democracia e reforma do Estado: paradoxos e alternativas analíticas". In: MELO RICO, E. e RAICHELIS, R. (orgs.). Gestão social - uma questão em debate. São Paulo, Educ/ IEE, 1999.

FIEP/FIESC/FIERGS. Comissão Fórum Sul do Mercosul. Diagnóstico da região sul frente ao Mercosul, 1997.

FOLHA DE S.PAULO, 10/10/2001.

GINESTA, J. El Mercosur y su contexto regional e internacional. Porto Alegre, Universidade/UFRGS, 1999.

GOUDARD, G.; JORDAN, D. "L'espace mondial face à la deuxième vague des unions régionales". In: CÉLIMENE, F. e LACOUR, C. (dir.) L'intégration régionale des espaces. Paris, Economica, 1997.

GÓMEZ, J.M. "Globalização, Estado-Nação e cidadania". Contexto Internacional. Rio de Janeiro, IRI/PUC Rio, v.20, n.1, jan.-jun. 1998.

HIRST, M. "Dimensão política do Mercosul: atores, politização e ideologia". In: ZYLBERSTAJN, H. et alii (eds.). Processos de integração regional e a sociedade. Rio de Janeiro, Paz e Terra, 1996.

LACHMANN, J. L'Action économique régionale. Paris, Economica, 1997.

LIMA, M. e MEDEIROS, M. (eds.). O Mercosul no limiar do Século XXI. São Paulo, Cortez, 2000.

LINS, H.N. e BERCOVICH, N.A. "Cooperação envolvendo pequenas e médias empresas industriais no Mercosul”. Ensaios FEE. Porto Alegre, 1995.

NICOLETTI, V. Mercosur y identidad cultural latinoamericana. Buenos Aires, Lugar, 1998.

NOGUEIRA, M.A. "Um Estado para a sociedade civil". In: MELO RICO, E. e RAICHELIS, R. (orgs.). Op. cit., 1999.

PASQUARIELlO MARIANO, K.L. A atuação da Comissão Parlamentar Conjunta e do Subgrupo de Trabalho-10 no Mercosul. Tese de Doutorado. Campinas, Unicamp, Instituto de Filosofia e Ciências Humanas, mar. 2001.

PIT-CNT/Fundación FESUR Uruguay. Curso Taller las dimensiones del Mercosur y las trabajadoras. Montevidéu, 1999.
PRINCÍPIOS éticos y políticos para las organizaciones profesionales de Trabajo Social del Mercosur. Buenos Aires, Reunião congregando associações de serviço social dos quatro países constitutivos e do Chile, 1999, mimeo.

RAICHELIS, R. Esfera pública e Conselhos de Assistência Social: caminhos da construção democrática. São Paulo, Cortez, 1998.

SIROËN, J.-M. La régionalisation de l'économie mondiale. Paris, La Découverte, 2000.

TOMAZONI, F.R. "O empresariado da região sul: sua visão e participação no processo de integração regional do Mercosul". Bolsa de iniciação científica. $2^{\circ}$ Relatório Científico. São Paulo, Fundap/ Cedec/PUC-SP, abr. 2001.

TROTTA, M.E.V. "Os trabalhadores e a integração regional". $2^{\circ}$ Relatório Científico. São Paulo, Fundap/Cedec/PUC-SP, abr. 2001.

VIGEVANI, T. e VEIGA, J.P. "Mercosul e os interesses políticos e sociais". São Paulo em Perspectiva. São Paulo, Fundação Seade, v.5, n.3, jul.-set. 1991.

WANDERLEY, L.E.W. "Rumos da ordem pública no Brasil: a construção do público". São Paulo em Perspectiva. São Paulo, Fundação Seade, v.10, n.4, out.-dez. 1996.

. "Desafios da sociedade civil brasileira em seu relacionamento dialético com o Estado e o Mercado". In: MELO RICO, E. e RAICHELIS, R. (orgs.). Gestão social - uma questão em debate. São Paulo, Educ/IEE, 1999.

WANDERLEY, L.E.W. e RAICHELIS, R. "Gestão pública democrática no contexto do Mercosul”. In: SIERRA, G. de (compilador). Los rostros del Mercosur - el difícil camino de lo comercial a lo societal. Buenos Aires, Clacso, 2001.

WEIDENFELD, W. e WESSELS, W. (orgs.). A Europa de A a Z-Guia da integração européia. Luxemburgo, Publicações Oficiais das Comunidades Européias, 1997.

Luiz Eduardo W. Whanderley: Professor da PUC-SP. Foi reitor da PUC$S P$. Autor, entre outros, O que é Universidade? 